OPEN ACCESS

Edited by: Brian Godman, Karolinska Institutet (KI),

Sweden

Reviewed by:

Olayinka Olabode Ogunleye, Lagos State University,

Nigeria

Amos Yared Massele, University of Botswana,

Botswana

*Correspondence:

Te L

at1029@163.com

Specialty section: This article was submitted to Pharmaceutical Medicine and

Outcomes Research,

a section of the journal Frontiers in Pharmacology

Received: 30 August 2019 Accepted: 17 March 2020

Published: 03 April 2020

Citation: Li X and Li T (2020) Combined Methods (Formal Adjusted Indirect Comparison, Meta-Analysis and Principal Component Analysis) Comparisons of the Safety and Efficacy of Ambrisentan, Bosentan, and Sildenafil in the Patients With Pulmonary Arterial Hypertension.

Front. Pharmacol. 11:400 doi: 10.3389/fphar.2020.00400

\section{Combined Methods (Formal Adjusted Indirect Comparison, Meta-Analysis and Principal Component Analysis) Comparisons of the Safety and Efficacy of Ambrisentan, Bosentan, and Sildenafil in the Patients With Pulmonary Arterial Hypertension}

\author{
Xinmei $L i$ and $T e L i$ * \\ Department of Pharmacy, Fuwai Yunnan Cardiovascular Hospital, Kunming, China
}

Background: Three oral drugs (ambrisentan, bosentan, and sildenafil) have been widely used to treat patients with pulmonary arterial hypertension (PAH). 1) There are no studies that directly compare the safety and efficacy of these three drugs. Existing studies could not meet the physician's need to select the most beneficial drugs for patients. 2) Principal component analysis is mainly used for scale analysis and has not been reported in clinical field. 3) When the results of the indirect meta-analysis were not satisfactory, no new solutions have been proposed in existing meta-analysis studies.

Methods: The overall process of this study is divided into 4 steps 1) literature search and data extraction; 2) principal component analysis; 3) common reference-based indirect comparison meta-analysis; 4) formal adjusted indirect comparison.

Results: Nine randomized controlled trials (RCTs) experiments and eight long-term experiments were selected. The main influencing factors are mortality, 6-min walk distance (6MW), mean pulmonary arterial pressure (PAP), cardiac index $(\mathrm{Cl})$ by principal component analysis. There was no significant heterogeneity among the indirect meta-analysis of three drugs. But in the formal adjusted indirect comparison 1) the level of PAP of sildenafil group $(60.5 \pm 22.35,220)$ was higher than that of the other three groups, placebo $(53.5 \pm 17.63,507)(p<0.001)$, ambrisentan $(49.5 \pm 15.08,130)(p<0.001)$, and bosentan $(54.6 \pm 118.41,311)(p<0.001) ; 2)$ the level of $\mathrm{Cl}$ of sildenafil group $(54 \pm 18,311)$ was higher than that of the other three groups, placebo $(2.7 \pm 1.09,518)(p<0.001)$, ambrisentan $(2.5 \pm 0.75,130)(p<0.001)$, and bosentan $(2.5 \pm 1.06,333)(p<0.001)$. In addition, sildenafil significantly improved the survival rate comparing with ambrisentan and bosentan.

Conclusions: The results of this study suggest that sildenafil might be more suitable for long-term treatment of PAH patients than ambrisentan and bosentan. In order to enable 
clinicians to draw conclusions more quickly and directly in the data-rich literature, we suggest the use of principal component analysis combined with formal adjusted indirect comparison to compare the efficacy and safety of drugs.

Keywords: ambrisentan, bosentan, sildenafil, principal component analysis, formal adjusted indirect comparison

\section{INTRODUCTION}

Pulmonary arterial hypertension $(\mathrm{PAH})$ is a progressive disease, which may involve multiple clinical conditions and can complicate the majority of cardiovascular and respiratory diseases. It is mainly characterized by elevated pulmonary arterial pressures (PAP) and vascular resistance. The increase of PAP, PAP $\geqq 25 \mathrm{mmHg}$ at rest, could be assessed by right heart catheterization. Research showed that the survival rates was $68.0 \%$ in 1 year, $38.9 \%$ in 3 years, and $20.8 \%$ in 5 years (Zhi-Cheng et al., 2007). In other words, PAH is a serious chronic life-threatening disease.

In the past decade, traditional supportive therapy (oral anticoagulants, diuretic, $\mathrm{O}_{2}$, digoxin) has failed to improve the patient survival rate, while specific drug therapy has become a more widely accepted long term treatment modality in recent years. As recommended by the 2015 ESC/ERC guidelines, drugs including ambrisentan, bosentan, and sildenafil were class IA for efficacy of oral monotherapy drug (Nazzareno et al., 2016). Among them, bosentan and ambrisentan could antagonize the endothelial dysfunction, in which endothelin-1 has been found to be overexpressed in PAH patients (Giaid et al., 1993). Bosentan is the first synthetic molecule of its class and a dual endothelin-1 receptor type $\mathrm{A}$ and $\mathrm{B}$ antagonist. Ambrisentan preferentially binds type A. The third drug, sildenafil, is a selective inhibitor of phosphodiesterase type 5. Eventually, the treatment of PAH with the above three drugs could result in vasodilation through pathway such as endothelin (ET) pathway and nitric oxide (NO) pathway (Galie et al., 2004; Benedetta et al., 2005; John et al., 2005).

Recently, although some meta-analyses and systematic reviews of individual drugs have been published, in which they have typically been compared with placebo. However, there have been no large randomized controlled trials comparing the drugs to one another reported, while too many indicators of the safety and efficacy are used. In the absence of directly comparable studies, it is difficult for general practitioners and cardiologists to directly select the most beneficial and safe treatment. In addition, indirect meta-analysis of the three drugs has not been reported in $\mathrm{PAH}$ patients. The purpose of this study is to combine three analysis methods, such as formal adjusted indirect comparison, meta-analysis, and principal component analysis, to analyze the treatment options for PAH patients. We sought to provide a direct and quick analytical method to assist patients and clinicians decide in clinical practice.

\section{MATERIALS AND METHODS}

The overall process of this study is divided into four steps: 1) literature search and data extraction; 2) principal component analysis; 3) common reference-based indirect comparison metaanalysis; 4) formal adjusted indirect comparison (Figure 1).

\section{Literature Search and Inclusion Criteria}

We primarily performed an exhaustive search of studies examining the efficacy and safety of ambrisentan, bosentan, and sildenafil in patients with $\mathrm{PAH}$. The literature was searched using MEDLINE, EMBASE, CNKI, WANFANG, and Cochrane Library (up to May 2019). The following keywords and subject terms were used in the searches: ambrisentan, bosentan, sildenafil, pulmonary arterial hypertension. Randomized controlled trials (RCTs) which met the following criteria were included in this study: 1) the study compared oral monotherapy drug, ambrisentan, bosentan, and sildenafil, with a placebo for $\mathrm{PAH} ; 2)$ the study provided endpoints for the clinical efficacy and safety; 3) the publication was in Chinese or English. The exclusion criteria were as follows: 1) Studies conducted in vitro experiments and animal studies, 2) the study used combination

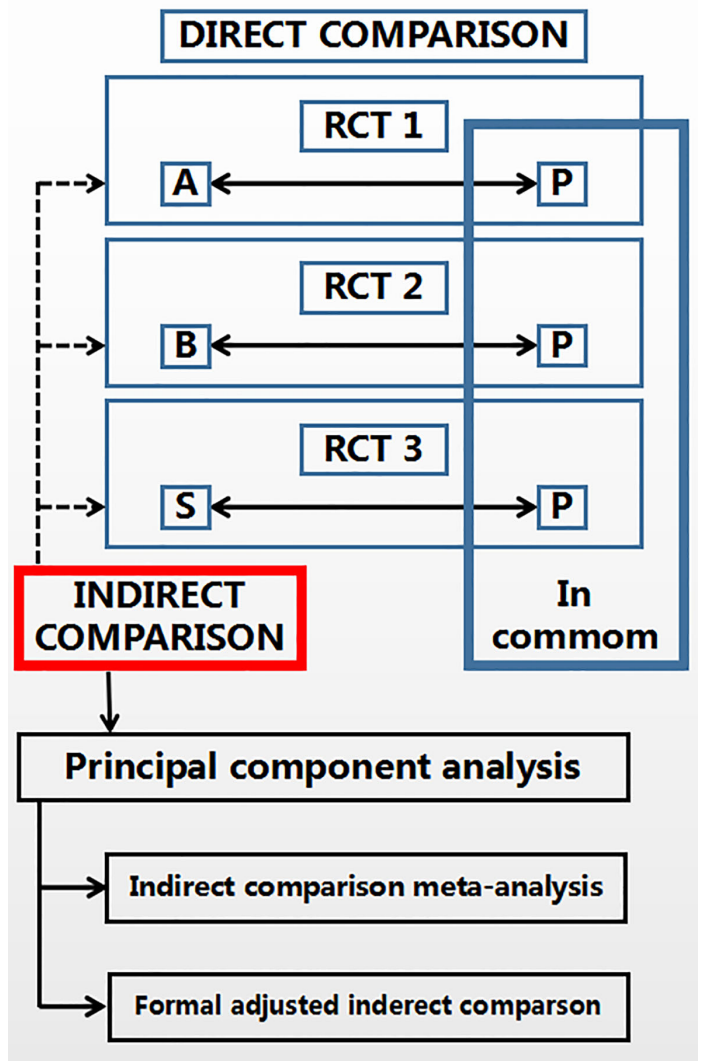

FIGURE 1 | Study flow diagram 
multidrug therapy such as iloprost, and 3) the study included duplicated data or did not contain adequate data for inclusion. Safety outcomes were mortality. As recommended by the 2015 ESC/ERC guidelines, efficacy outcomes were as follows: 1) 6-min walk distance $(6 \mathrm{MW}), 2)$ mean pulmonary arterial pressure (PAP), 3) cardiac index (CI), 4) Pulmonary vascular resistance index (PVR), and 5) mean right atrial pressure (RAP).

\section{Data Extraction and Quality Assessment}

According to the recommended guidelines of the Cochrane Handbook for Systematic Reviews, the extraction form, created with Microsoft Excel, included initial author's name, year of publication, study site, study design, mean age of participants, and sample size, dose, length of follow-up, and efficacy and safety outcomes and so on. We quantified the methodological qualities of the studies using Jadad scores. These assessments were based on the following 3 criteria: 1 ) whether the randomization method was appropriate, 2) whether double blindness was mentioned in the trial and the trial was appropriately performed, and 3) whether the number of patients that withdrew or dropped out, and the reasons for this, were clearly stated.

The two authors carried out independent reviews. Discrepancies between the reviewers were resolved through consensus. The reviewers assessed the methodological quality of each study by using the risk of bias method recommended by the Cochrane Collaboration.

\section{Statistical Analysis}

We chose dichotomous primary outcomes to have hard outcome measures of treatment efficacy. Analyses were conducted using Excel, R 3.6.0 (principal component analysis), StataSE 15 (common reference-based indirect comparison meta-analysis), and GraphPad Prism 6 (formal adjusted indirect comparison).

\section{Principal Component Analysis}

The purpose of principal component analysis was to describe the relationship among many indicators with a small number of principal components (Wangzong and Jiahong, 2014). In this study, the software R 3.6.0 was utilized for the principal component analysis of the extracted indicators such as mortality, 6MW, PAP, CI, PVR, and RAP. When the sum of the influencing factors is $\geqq 85 \%$, the influencing factors are considered as the principal component.

\section{Common Reference-Based Indirect Comparison Meta-analysis}

Differences among ambrisentan, bosentan, and sildenafil were assessed by odds ratio (OR) with $95 \%$ confidence intervals (CIs). The random-effect model was used to calculate OR (Dersimonian and Laird, 1986). The possibility of publication bias was estimated by funnel plots. Heterogeneity among studies was evaluated by calculating $p$-value and the $I^{2}$ measure of inconsistency, which was considered significant if $p<0.10$ or $I^{2}>50 \%$. All calculations were carried out using StataSE 15. Results were considered as statistically significant when the $p$ value was $<0.05$. Common reference-based indirect comparisons were performed using the method suggested by Xiantao $\mathrm{Z}$
(Xiantao and Xuequn, 2017): the indirect comparison of ambrisentan, bosentan, and sildenafil was adjusted by the results of their direct comparisons with placebo.

\section{Formal Adjusted Indirect Comparison}

According to the group of placebo and drug administration, the mean, sd, and $\mathrm{n}$ values of main indicators from principal component analysis were formal adjusted by formula 1 , formula 2, and formula 3 (Jiahong and Tianhe, 2010). The combination formula 1 of two data (Supplementary Text 1):

$$
M=\frac{\left(\mathrm{N}_{1} \mathrm{M}_{1}+\mathrm{N}_{2} \mathrm{M}_{2}\right)}{\left(\mathrm{N}_{1}+\mathrm{N}_{2}\right)}
$$

The combination formula 2 of two data:

$\mathrm{SD}=\sqrt{\frac{\left(\mathrm{N}_{1}-1\right) \mathrm{SD}_{1}^{2}+\left(\mathrm{N}_{2}-1\right) \mathrm{SD}_{2}^{2}+\frac{\mathrm{N}_{1} \mathrm{~N}_{2}}{\mathrm{~N}_{1}+\mathrm{N}_{2}}\left(\mathrm{M}_{1}^{2}+\mathrm{M}_{2}{ }^{2}-2 \mathrm{M}_{1}^{2} \mathrm{M}_{2}^{2}\right)}{\mathrm{N}_{1}+\mathrm{N}_{2}-1}}$

The combination formula 3 of two data:

$$
\mathrm{N}=\mathrm{N}_{1}+\mathrm{N}_{2}
$$

And multiple $t$ tests and graphs of each safety indicators of drugs were applied in GraphPad Prism 6. Comparing p-values between groups and results were considered as statistically significant when the $p$-value was $<0.05$.

\section{RESULT}

Figure 2 presents a flowchart describing the trial screening and selection procedure. After the search strategy, nine reports were included in this systematic review (Channick et al., 2001; Lewis et al., 2002; Humbert et al., 2004; Nazzareno et al., 2006; Galiè et al., 2008; Barst et al., 2010; Robyn et al., 2011; Carmine et al., 2017; Nazzareno et al., 2018). A total of six studies compared bosentan versus placebo, two studies compared sildenafil versus placebo, and one study compared ambrisentan versus placebo. Table 1 summarizes the methodological quality of the included trials.

\section{Principal Component Analysis}

According to the result (Table 2 ) from R 3.6.0, the product of the eigenvalue corresponding to each principal component and proportion of variance is used to calculate the comprehensive model of principal component. The principal component formula (Supplementary Text 2):

$$
\begin{aligned}
\mathrm{F}= & \mathrm{F} 1 \times 0.3995+\mathrm{F} 2 \times 0.2372+\mathrm{F} 3 \times 0.1526+\mathrm{F} 4 \times 0.1375 \\
& +\mathrm{F} 5 \times 0.00650+\mathrm{F} 6 \times 0.00080
\end{aligned}
$$

Sum $=(0.3995+0.2372+0.1526+0.1375) \times 100 \%=92.85 \%$

$$
>85.00 \%
$$

The principal components are $\mathrm{F}_{1}$ (mortality), $\mathrm{F}_{2}(6 \mathrm{mw}), \mathrm{F}_{3}$ (PAP), and $\mathrm{F}_{4}(\mathrm{CI})$, which will be used to do the indirect 
5415 records identified through database searching; 4487 in English, 919 in Chinese, 9 in Cochrane Library

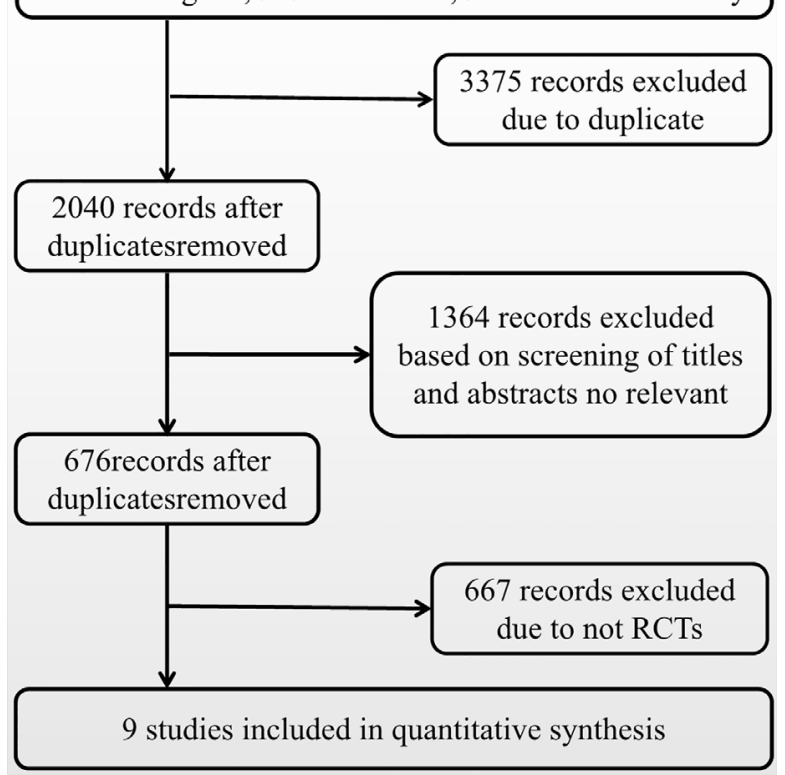

FIGURE 2 | Literature screening flow diagram

comparison. However, $\mathrm{F}_{5}(\mathrm{PVR})$ and $\mathrm{F}_{6}(\mathrm{RAP})$ are screened and removed without further discussion.

\section{Common Reference-Based Indirect Comparison Meta-analysis} Statistical Analysis of Efficacy Outcomes (6MW, PAP, Cl)

Mean Difference (MD) was available for the $6 \mathrm{MW}, \mathrm{PAP}$, and CI trials. The statistics of the pooled analysis of MD using the random-effects model is showed in Table 3. Only the data from the CI trail, including treatment with ambrisentan, bosentan, and sildenafil, showed favorable results with an MD of -0.7 (95\% CI, -1.11 to -0.29$)$. Further subgroup analysis of CI revealed that the heterogeneity mainly came from all three drugs (Figure 3 ). The $\mathrm{MD}$ of ambrisentan, bosentan, and sildenafil subgroup is -0.05 (95\% CI, -0.32 to 0.14 ), 0.09 (95\% CI, 0 to 0.18 ), and -0.26 (95\% $\mathrm{CI},-0.07$ to 0.15$)$, respectively. The overall difference in the CI group was mainly from the ambrisentan and bosentan subgroups.

The indirect comparison $\mathrm{OR}$ of the 6MW, PAP, and CI for ambrisentan versus bosentan, ambrisentan versus sildenafil, bosentan versus sildenafil is in Table 4. But there was no significant heterogeneity between the indirect comparison of ambrisentan, bosentan, and sildenafil.

\section{Statistical Analysis of Safety Outcomes on Long Term (Mortality)}

Since no deaths occurred in the sildenafil groups, ambrisentan and bosentan could not be directly compared with sildenafil in the short-term mortality. Therefore, we combined eight longterm studies of mortality of three drugs for comparison of the differences (Figure 4) (Lewis et al., 2000; Antonio et al., 2006; Ronald et al., 2009; Shannon et al., 2010; Wouter et al., 2010; Michele et al., 2012; Shunji et al., 2012; Robyn et al., 2014). In these studies, patients with PAH were treated with ambrisentan, bosentan, and sildenafil from 12 weeks to 3 years. A research assessed the survival rates at $68.0 \%$ in 1 year and $38.9 \%$ in 3 years (Zhi-Cheng et al., 2007). Comparison with this research, ambrisentan and sildenafil increased the 1-year survival rate by $83 \%$ and $97 \%$. Only sildenafil increased the 3-year survival rate by $83 \%$.

\section{Formal Adjusted Indirect Comparison}

After combined Mean, SD, and $\mathrm{N}$ by formula 1, formula 2, and formula 3 (Table 5), multiple t test showed more differences in $6 \mathrm{MW}, \mathrm{PAP}, \mathrm{CI}$ indicators than the indirect comparison metaanalysis (Figure 5). The difference between the four groups was very small in the comparison of 6WM indicator. The level

TABLE 1 | Characteristics and the quality assessment of the nine studies included.

\begin{tabular}{|c|c|c|c|c|c|c|c|c|c|c|}
\hline Study, year & Drug & Abbr. & $\begin{array}{l}\text { Patients } \\
\text { (N) }\end{array}$ & Term & $\begin{array}{c}\text { Random sequence } \\
\text { generation }\end{array}$ & $\begin{array}{c}\text { Allocation } \\
\text { concealment }\end{array}$ & Blinding & $\begin{array}{l}\text { Incomplete outcome } \\
\text { data addressed }\end{array}$ & $\begin{array}{l}\text { Selective } \\
\text { reporting }\end{array}$ & $\begin{array}{l}\text { Other } \\
\text { bias }\end{array}$ \\
\hline \multirow{2}{*}{$\begin{array}{l}\text { Nazzareno et } \\
\text { al., } 2018\end{array}$} & \multirow[t]{2}{*}{ Ambrisentan } & A1-1 & 201 & 12 weeks & Yes & Yes & Unclear & Yes & Yes & Unclear \\
\hline & & A1-2 & 192 & 12 weeks & Yes & Yes & Unclear & Yes & Yes & Unclear \\
\hline $\begin{array}{l}\text { Channick, } \\
2001\end{array}$ & \multirow[t]{5}{*}{ Bosentan } & $\mathrm{B} 1$ & 32 & 20 weeks & Yes & Yes & Unclear & Yes & No & Unclear \\
\hline $\begin{array}{l}\text { Barst et al., } \\
2010\end{array}$ & & $\mathrm{~B} 2$ & 14 & 16 weeks & Yes & Yes & Unclear & No & Unclear & Unclear \\
\hline Galiè, 2008 & & B3 & 185 & 6 months & Yes & Yes & Yes & Yes & Yes & Unclear \\
\hline \multirow[t]{2}{*}{ Lewis, 2002} & & B4-1 & 213 & 16 weeks & Yes & Yes & Unclear & Yes & Unclear & Unclear \\
\hline & & B4-2 & 33 & 16 weeks & Yes & Yes & Unclear & Yes & Unclear & Unclear \\
\hline $\begin{array}{l}\text { Humbert et al., } \\
2004\end{array}$ & & B5 & 33 & 16 weeks & Yes & Yes & Unclear & Yes & Unclear & Unclear \\
\hline $\begin{array}{l}\text { Nazzareno et } \\
\text { al., } 2006\end{array}$ & & B6 & 54 & 16 weeks & Yes & Yes & Yes & Yes & Unclear & Unclear \\
\hline Robyn, 2011 & Sildenafil & S1 & 234 & 16 weeks & Yes & Yes & Unclear & Yes & Unclear & Unclear \\
\hline Carmine et al., & & $\mathrm{S} 2$ & 86 & 24 weeks & Yes & Yes & Unclear & Yes & Unclear & Unclear \\
\hline
\end{tabular}


TABLE 2 | Importance of components by principal component analysis.

\begin{tabular}{|c|c|c|c|c|c|c|}
\hline & Mortality & $6 m w$ & PAP & $\mathrm{Cl}$ & PVR & RAP \\
\hline Standard deviation & 1.5483 & 1.1931 & 0.9569 & 0.9085 & 0.6246 & 0.2197 \\
\hline Proportion of Variance & 0.3995 & 0.2372 & 0.1526 & 0.1375 & 0.0650 & 0.0080 \\
\hline Cumulative Proportion & 0.3995 & 0.6367 & 0.7893 & 0.9269 & 0.9919 & 1.0000 \\
\hline
\end{tabular}

TABLE 3 | Mean difference (MD) result of meta-analysis for the 6MW, PAP, and Cl trials by software RevMan.

\begin{tabular}{|c|c|c|c|c|c|c|c|c|c|}
\hline \multirow[b]{2}{*}{$6 \mathrm{MW}$} & \multirow{2}{*}{$\begin{array}{c}\text { MD } \\
-5.38\end{array}$} & \multicolumn{2}{|c|}{ Cls (95\%) } & \multirow{2}{*}{$\begin{array}{c}\text { Chi2 } \\
5.48\end{array}$} & \multirow{2}{*}{$\frac{\mathbf{d f}}{7}$} & \multirow{2}{*}{$\begin{array}{c}\mathbf{P} \\
0.6\end{array}$} & \multirow{2}{*}{$\frac{12(\%)}{0}$} & \multirow{2}{*}{$\frac{\mathbf{Z}}{1.03}$} & \multirow{2}{*}{$\frac{\mathbf{P}}{0.3}$} \\
\hline & & -15.66 & 4.89 & & & & & & \\
\hline PAP & -0.87 & -2.7 & 0.95 & 16.61 & 9 & 0.06 & 46 & 0.94 & 0.35 \\
\hline $\mathrm{Cl}$ & -0.7 & -1.11 & -0.29 & 25.39 & 10 & 0.005 & 61 & 2.37 & 0.02 \\
\hline
\end{tabular}

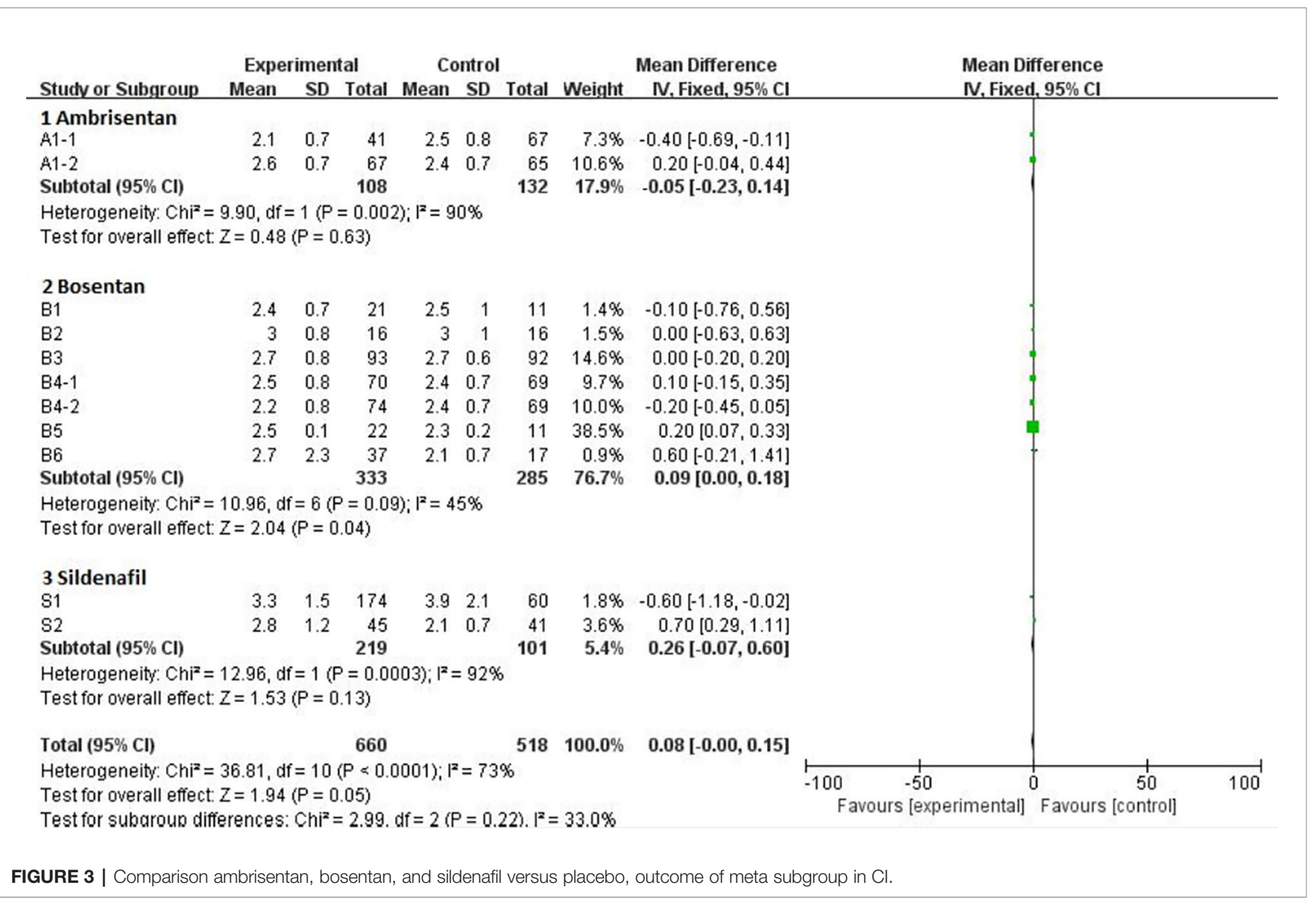

of bosentan group $(371 \pm 95,307)$ was slightly higher than that of ambrisentan group $(347 \pm 80,130)(\mathrm{p}<0.05)$ and sildenafil group $(340 \pm 76,45)(\mathrm{p}<0.05)$. In the comparison of PAP data, the level of sildenafil group $(60.5 \pm 22.35,220)$ was higher than that of the other three groups, placebo $(53.5 \pm$ $17.63,507)(\mathrm{p}<0.001)$, ambrisentan $(49.5 \pm 15.08,130)(\mathrm{p}<$ $0.001)$, and bosentan $(54.6 \pm 118.41,311)(\mathrm{p}<0.001)$. In the comparison of CI data, the level of sildenafil group (54 \pm 18 , 311) was higher than that of the other three groups, placebo $(2.7 \pm 1.09,518)(\mathrm{p}<0.001)$, ambrisentan $(2.5 \pm 0.75,130)(\mathrm{p}$ $<0.001)$, and bosentan $(2.5 \pm 1.06,333)(\mathrm{p}<0.001)$.

\section{DISCUSSION}

\section{Discussion of the Safety and Efficacy of Three Drugs}

Currently, the pathways for the oral treatments of $\mathrm{PAH}$ are mainly divided into two types: ET pathway and NO pathway. ET and NO are two of the most important vasoconstrictor and vasoconstrictor factors. Under normal conditions, both factors work together to maintain the normal state and function of blood vessels (Kawanabe and Nauli, 2011). However, in pulmonary hypertensive disorders, it is reported that ET-1 receptor type A is 
TABLE 4 | The indirect meta-analysis of the 6MW, PAP, and $\mathrm{Cl}$ for ambrisentan versus bosentan, ambrisentan versus sildenafil, bosentan versus sildenafil by software STATA.

\begin{tabular}{ccccccc}
\hline & & $\begin{array}{c}\text { Exponential } \\
\text { Statistic OR }\end{array}$ & \multicolumn{2}{c}{ Cls (95\%) } & Chi2 & P \\
\hline \multirow{2}{*}{$6 \mathrm{MW}$} & A vs B & 0.112 & 0 & 2933.422 & 0.178 & 0.673 \\
& A vs S & 0 & 0 & 5.437 & 2.6 & 0.107 \\
& B vs S & 0.003 & 0 & 60.005 & 1.294 & 0.255 \\
PAP & A vs B & 2.466 & 0 & $2.99 E+08$ & 0.009 & 0.924 \\
& A vs S & 0.513 & 0 & 20323.13 & 0.015 & 0.902 \\
& B vs S & 1.077 & 0 & 40807.864 & 0 & 0.989 \\
Cl & A vs B & 1.208 & 0 & $1.60 E+36$ & 0 & 0.996 \\
& A vs S & 0.985 & 0.272 & 3.566 & 0.001 & 0.982 \\
& B vs S & 0.988 & 0 & 0.274 & 1.27 & 0.985 \\
\hline
\end{tabular}

abnormally activated, NO synthase gene expression, and NO signaling are reduced (Stephen et al., 2007). Bosentan blocks ET1 receptor type $\mathrm{A}$ and $\mathrm{B}$, and ambrisentan blocks $\mathrm{ET}-1$ receptor type A. Sildenafil mainly enhances NO and cyclic guanosine phosphate signaling pathways. In this study, sildenafil significantly improved the survival rate comparing with ambrisentan and bosentan as shown in Figure 4, and the value of PAP and CI was higher than ambrisentan and bosentan as shown in Figure 5. This finding suggests that the higher value of PAP and CI may imply lower mortality. However, some researchers suggest that PAP only provides little prognostic information and $\mathrm{CI}$ is a robust indicator of hemodynamics (Sitbon et al., 2005; Nickel et al., 2012). Some even suggest that

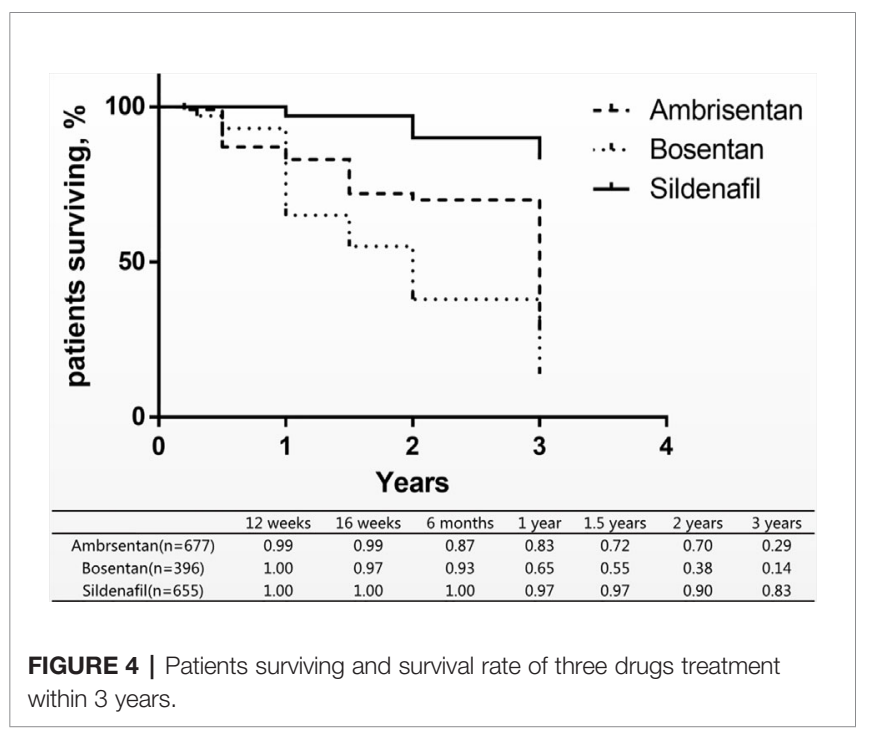

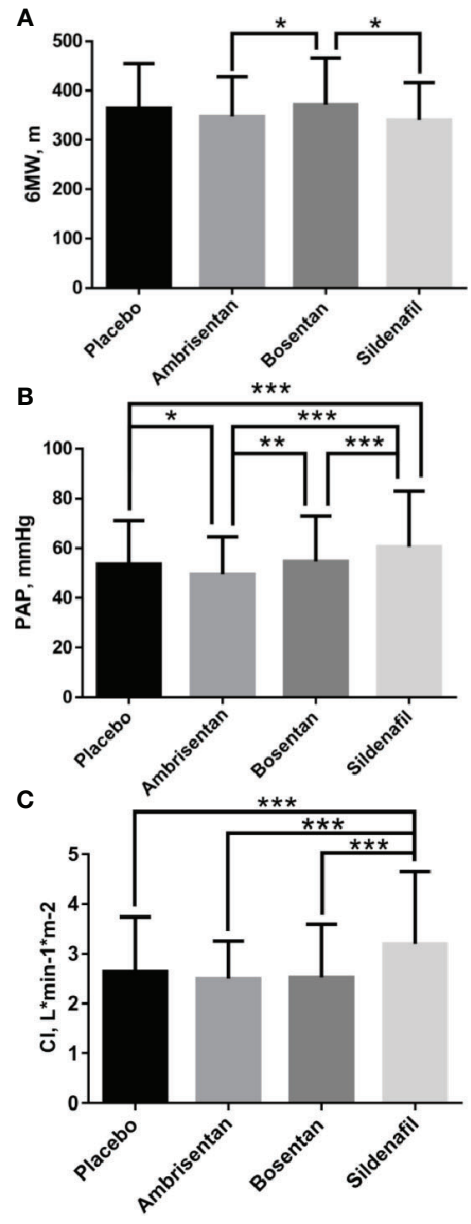

FIGURE 5 | Comparative differences of multiple t test of 6MW (A), PAP (B), and $\mathrm{Cl}$ (C). Statistical analysis was performed using multiple t test. ${ }^{*} \mathrm{P}<0.05$; ${ }^{\star \star} \mathrm{P}<0.01 ;{ }^{\star \star \star} \mathrm{P}<0.001$

the estimated PAP is not relevant for therapeutic making (Raymond et al., 2010). Therefore, the finding of this study is very interesting and awaits independent confirmation. In addition, the finding of this study may imply that choosing NO pathway may be more effective and safer than the ET pathway in the PAH treatment. There are 10 drugs in the ET pathway and 14 drugs in the NO pathway from drugbank.ca. Therefore, this finding also awaits further confirmation.

As shown in Figure 5, the comparison of 6MW values shows no significant difference. Some researchers assert that may due to the placebo effect in the RCTs (Carmine et al., 2017). 6WM is a

TABLE 5 | Formal adjusted results (Mean, SD, N) of the 6MW, PAP, and Cl by formula 1, formula 2, and formula 3 .

\begin{tabular}{|c|c|c|c|c|c|c|c|c|c|c|c|c|}
\hline & \multicolumn{3}{|c|}{ Placebo } & \multicolumn{3}{|c|}{ Ambrisentan } & \multicolumn{3}{|c|}{ Bosentan } & \multicolumn{3}{|c|}{ Sildenafil } \\
\hline & Mean & SD & $\mathbf{N}$ & Mean & SD & $\mathbf{N}$ & Mean & SD & $\mathbf{N}$ & Mean & SD & $\mathbf{N}$ \\
\hline $6 \mathrm{MW}$ & 363.5174 & 91.2368 & 451 & 347.7846 & 80.9527 & 130 & 371.0963 & 95.2210 & 307 & 340.0000 & 76.0000 & 45 \\
\hline PAP & 53.5020 & 17.6330 & 507 & 49.5462 & 15.0812 & 130 & 54.6645 & 18.4091 & 311 & 60.5118 & 22.3599 & 220 \\
\hline $\mathrm{Cl}$ & 2.6502 & 1.0873 & 518 & 2.5031 & 0.7539 & 130 & 2.5291 & 1.0636 & 333 & 3.1973 & 1.4551 & 219 \\
\hline
\end{tabular}


TABLE 6 | Determination of six indicators in 11 studies.

\begin{tabular}{|c|c|c|c|c|c|c|c|c|c|c|c|c|c|c|c|c|c|c|}
\hline & & \multicolumn{2}{|c|}{ Mortality } & \multicolumn{3}{|c|}{$6 \mathrm{MW}, \mathrm{m}$} & \multicolumn{3}{|c|}{ PAP, mmHg } & \multicolumn{3}{|c|}{$\mathrm{Cl}, \mathrm{L} \bullet \mathrm{min}-1 \bullet \mathrm{m}-2$} & \multicolumn{3}{|c|}{ PVR, wood units } & \multicolumn{3}{|c|}{ RAP, mmHg } \\
\hline & & $\mathbf{n}$ & $\mathbf{N}$ & mean & sd & $\mathbf{n}$ & mean & sd & $\mathbf{n}$ & mean & sd & $\mathbf{n}$ & mean & sd & $\mathbf{n}$ & mean & sd & $\mathbf{n}$ \\
\hline \multirow[t]{11}{*}{ Placebo } & $\mathrm{A} 1-1$ & 2 & 67 & 342 & 73 & 73 & 50.0 & 15.0 & 67 & 2.5 & 0.8 & 67 & 10.85 & 6.48 & 67 & 8.0 & 5.0 & 67 \\
\hline & A1-2 & 4 & 65 & 343 & 86 & 65 & 51.0 & 13.0 & 65 & 2.4 & 0.7 & 65 & 12.14 & 7.24 & 65 & 7.0 & 5.0 & 65 \\
\hline & B1 & 0 & 11 & 355 & 82 & 11 & 56.0 & 10.0 & 11 & 2.5 & 1 & 11 & 11.78 & 5.38 & 11 & 9.9 & 4.1 & 11 \\
\hline & & B2 & 0 & 8 & 353 & 170 & 14 & 38.0 & 7.0 & 16 & 3 & 1 & 16 & 5.44 & 2.36 & 16 & NA & NA \\
\hline & B3 & 1 & 92 & 431 & 91 & 92 & 52.3 & 16.0 & 92 & 2.7 & 0.6 & 92 & 10.06 & 4.61 & 92 & 7.5 & 5.1 & 92 \\
\hline & B4-1 & 2 & 69 & 344 & 76 & 69 & 53.0 & 17.0 & 69 & 2.4 & 0.7 & 69 & 11.00 & 6.75 & 69 & 8.9 & 5.1 & 69 \\
\hline & B4-2 & 0 & 11 & 344 & 76 & 69 & 53.0 & 17.0 & 69 & 2.4 & 0.7 & 69 & 11.00 & 6.75 & 69 & 8.9 & 5.1 & 69 \\
\hline & B5 & 0 & 11 & NA & NA & NA & NA & NA & NA & 2.3 & 0.2 & 11 & 13.13 & 1.93 & 11 & NA & NA & NA \\
\hline & B6 & 0 & 17 & 366 & 68 & 17 & 72.1 & 19.4 & 17 & 2.1 & 0.7 & 17 & 17.94 & 7.56 & 17 & 5.0 & 3.7 & 17 \\
\hline & S1 & 0 & 60 & NA & NA & NA & 59.0 & 22.0 & 60 & 3.9 & 2.1 & 60 & 15.00 & 10.00 & 60 & 8.0 & 5.0 & 60 \\
\hline & S2 & 0 & 41 & 348 & 67 & 41 & 57.2 & 21.9 & 41 & 2.1 & 0.7 & 41 & 15.70 & 9.90 & 41 & 10.5 & 5.1 & 41 \\
\hline \multirow[t]{11}{*}{ agents } & $\mathrm{A} 1-1$ & 1 & 134 & 341 & 78 & 67 & 51.0 & 16.0 & 67 & 2.6 & 0.7 & 67 & 11.40 & 5.81 & 67 & 9.0 & 6.0 & 67 \\
\hline & A1-2 & 2 & 127 & 355 & 84 & 63 & 48.0 & 14.0 & 63 & 2.4 & 0.8 & 63 & 11.64 & 8.40 & 63 & 8.0 & 5.0 & 63 \\
\hline & B1 & 0 & 21 & 360 & 86 & 21 & 54.0 & 13.0 & 21 & 2.4 & 0.7 & 21 & 11.20 & 5.31 & 21 & 9.7 & 5.6 & 21 \\
\hline & B2 & 1 & 6 & 370 & 122 & 12 & 31.0 & 6.0 & 16 & 3 & 0.8 & 16 & 4.90 & 2.25 & 16 & NA & NA & NA \\
\hline & B3 & 1 & 93 & 438 & 86 & 93 & 52.5 & 18.9 & 93 & 2.7 & 0.8 & 93 & 10.49 & 6.64 & 93 & 6.9 & 4.5 & 93 \\
\hline & B4-1 & 3 & 144 & 326 & 73 & 70 & 53.0 & 14.0 & 70 & 2.5 & 0.8 & 70 & 11.05 & 5.15 & 70 & 9.7 & 5.4 & 70 \\
\hline & B4-2 & 2 & 22 & 333 & 75 & 74 & 57.0 & 17.0 & 74 & 2.2 & 0.8 & 74 & 14.59 & 10.94 & 74 & 9.9 & 6.5 & 74 \\
\hline & B5 & 2 & 22 & NA & NA & NA & NA & NA & NA & 2.5 & 0.1 & 22 & 11.84 & 1.30 & 22 & NA & NA & NA \\
\hline & B6 & 0 & 37 & 332 & 83 & 37 & 77.8 & 15.2 & 37 & 2.7 & 2.3 & 37 & 21.41 & 8.82 & 37 & 6.1 & 3.4 & 37 \\
\hline & $\mathrm{S} 1$ & 0 & 174 & NA & NA & NA & 63.0 & 22.0 & 174 & 3.3 & 1.5 & 174 & 20.00 & 15.00 & 174 & 8.0 & 5.0 & 174 \\
\hline & S2 & 0 & 45 & 340 & 76 & 45 & 51.1 & 21.4 & 46 & 2.8 & 1.2 & 45 & 11.70 & 9.10 & 45 & 8.4 & 4.7 & 45 \\
\hline
\end{tabular}

NA means there is no relevant value in the references.

submaximal exercise test and influenced by several factors, including sex, age, need for $\mathrm{O}_{2}$, and motivation. The recent researches also showed no relationship between magnitude of exercise improvements and survival (Nazzareno et al., 2009; Alejandro et al., 2010). The results of the 6MW analysis are consistent with the results of the existing published studies.

\section{Discussion of the Combined Methods}

Principal component analysis was mainly used in scale analysis. This study, to the best of our knowledge, is the first to use principal component analysis to analyze clinical trial data. This study confirms that it is very feasible to screen out the main components from multiple factors and can be used in clinical field. This method could be extended by clinical data researchers to effectively screen out important disease-related biochemical information, especially those who analyze multiple laboratory biochemical results. This study has proved the practicality of this method in clinical research through experiments, which is of great significance. As shown in Table 6, when there are too many efficacy indicators, clinical researchers might randomly select these indicators in clinical trials, which would bring great difficulties to data analysis. We suggest that clinical researchers could use principal component analysis to screen published effective indicators when designing studies, which might be conducive to forming norms and even guidelines for indicators in this research area. If this method could be widely used in the clinical field, on the one hand, it might shorten the time for doctors to analyze the results of clinical trials, on the other hand, it might reduce the cost of patients for unimportant examination items.
This study first proposes the formal adjusted indirect comparison could be used as alternative method, when the results of the indirect meta-analysis were not satisfactory. The main advantage of meta-analysis software lies in the visualization of forest maps. However, when the difference between the placebo group and the treatment group is small, the visualization effect is significantly weakened, as shown in Figure 3 of this study. It could be clearly known through this study that formal adjusted indirect comparison resulted in more intuitive data results than indirect meta-analysis. Formal adjusted indirect comparison are graphically visualized using the software GraphPad Prism 6, which is easier to manipulate than meta-analysis software. This might be very friendly to researchers who may not have a background in meta-analysis, and can help them speed up the time to analyze data, especially for doctors who treat acute illnesses.

\section{CONCLUSION}

We indirectly compared the effectiveness and safety of ambrisentan, bosentan, and sildenafil, for the first time, and found that sildenafil might be more suitable for long-term treatment of $\mathrm{PAH}$ patients than ambrisentan and bosentan, because it can significantly improve the survival rate. In order to enable clinicians to draw conclusions more quickly and directly in the data-rich literature, we suggest the use of principal component analysis combine with formal adjusted indirect comparison to compare the efficacy and safety of drugs. 


\section{DATA AVAILABILITY STATEMENT}

The raw data supporting the conclusions of this manuscript will be made available by the authors, without undue reservation, to any qualified researcher.

\section{AUTHOR CONTRIBUTIONS}

XL: Data analysis, discussion, the meta-analysis methods and results, data extraction and quality control was performed. TL: The data extraction and quality control.

\section{REFERENCES}

Alejandro, M., Roberto, M., Gianni, T., Marco, S., Rosamaria, M., Luigi, T., et al. (2010). Systematic review of trials using vasodilators in pulmonary arterial hypertension: why a new approach is needed. Am. Heart J. 159, 245-257. doi: 10.1016/j.ahj.2009.11.028

Antonio, R., Pilar, G., Víctor, M., Carlos, B., Enric, D., and Ferran, M. (2006). Long-term Outcomes of Treatment With Bosentan in Pulmonary Hypertension. Arch. Bronconeumol 42 (12), 616-620. doi: 10.1185/ 03007995.2012.685930

Barst, R. J., Mubarak, K. K., and Machado, R. F. (2010). Exercise Capacity and Hemodynamics in Patients with Sickle Cell Disease with Pulmonary Hypertension Treated with Bosentan: Results of the ASSET studies. Br. J. Haematol. 149 (3), 426-435. doi: 10.1111/j.1365-2141.2010.08097.x

Benedetta, T., Alessandra, M., Emanuela, F., Carla, P., Carlo, G., Romano, Z., et al. (2005). Antiproliferative effect of sildenafil on human pulmonary artery smooth muscle cells. Basic Res. Cardiol. 100, 131-138. doi: 10.1007/s00395004-0504-5

Carmine, D. V., Sastry, B. K. S., Zeenat, S., Lutz, H., Xiang, G., Min, Z., et al. (2017). Efficacy of 1, 5, and $20 \mathrm{mg}$ oral sildenafil in the treatment of adults with pulmonary arterial hypertension: a randomized, double-blind study with openlabel extension. BMC Pulm. Med. 17, 44-56. doi: 10.1186/s12890-017-0374-x

Channick, R. N., Simonneau, G., Sitbon, O., Robbins, I. M., Frost, A., Tapson, V. F., et al. (2001). Effects of the dual endothelin-receptor antagonist bosentan in patients with pulmonary hypertension: a randomised placebo controlled study. Lancet 358, 1119-1123. doi: 10.1016/S0140-6736(01) 06250-X

Dersimonian, R., and Laird, N. (1986). Meta-analysis in clinical trials, Control. Clin. Trials 7, 177-188. doi: 10.1016/0197-2456(86)90046-2

Galiè, N., Rubin, L., Hoeper, M., Jansa, P., Al-Hiti, H., Meyer, G., et al. (2008). Treatment of patients with mildly symptomatic pulmonary arterial hypertension with bosentan (EARLY study): a double-blind, randomised controlled trial. Lancet 371, 2093-2100. doi: 10.1016/S0140-6736(08) 60919-8

Galie, N., Manes, A., and Branzi, A. (2004). The endothelin system in pulmonary arterial hypertension. Cardiovasc. Res. 61, 227-237. doi: 10.1016/ j.cardiores.2003.11.026

Giaid, A., Yanagisawa, M., Langleben, D., Michel, R. P., Levy, R., Shennib, H., et al. (1993). Expression of endothelin-1 in the lungs of patients with pulmonary hypertension. New Engl. J. Med. 328, 1732-1739. doi: 10.1056/ NEJM199306173282402

Humbert, M., Barst, R. J., Robbins, I. M., Channick, R. N., Galiè, N., Boonstra, A., et al. (2004). Combination of bosentan with epoprostenol in pulmonary arterial hypertension: BREATHE-2. Eur. Respir. Soc. 24, 353-359. doi: 10.1183/ 09031936.04.00028404

Jiahong, L., and Tianhe, X. (2010). Medical statistics (Beijing: Beijing Science Press).

John, W., Julian, W. S., Gigi, M., Ellena, J. G., Xiaohui, R., Angela, P. F., et al. (2005). Antiproliferative effects of phosphodiesterase type 5 inhibition in human pulmonary artery cells. Am. J. Respir. Crit. Care Med. 172, 105-113. doi: 10.1164/rccm.200411-1587OC

Kawanabe, Y., and Nauli, S. M. (2011). Endothelin. Cell. Mol. Life Sci. 68 (2), 195203. doi: $10.1007 / \mathrm{s} 00018-010-0518-0$

\section{ACKNOWLEDGMENTS}

We wish to thank the colleagues from pharmacy department of Fuwai Yunnan Cardiovascular Hospital for their support.

\section{SUPPLEMENTARY MATERIAL}

The Supplementary Material for this article can be found online at: https://www.frontiersin.org/articles/10.3389/fphar.2020.00400/ full\#supplementary-material

Lewis, J. R., David, B. B., Thomas, R. F., Nazzareno, G., Gerald, S., Hossein, A. G., et al. (2000). Long-term Treatment With Sildenafil Citrate in Pulmonary Arterial Hypertension. Chest 140 (5), 1274-1283.

Lewis, J. R., David, B. B., Robyn, J. B., Nazzareno, G., Carol, M. B., Anne, K., et al. (2002). Bosentan therapy for pulmonary arterial hypertension. New Engl. J. Med. 346 (12), 896-903. doi: 10.1378/chest.10-0969

Michele, D., Emanuele, R., Paola, A., Anna, C., Berardo, S., Giancarlo, S., et al. (2012). Ambrisentan for pulmonary arterial hypertension: Long term effects on clinical status, exercise capacity and haemodynamics. Int. J. Cardiol. 156 (2), 244-245. doi: 10.1016/j.ijcard.2012.01.054

Nazzareno, G., Maurice, B., Michael, A. G., John, G., Rolf, M. F., Andrea, L., et al. (2006). Bosentan Therapy in Patients With Eisenmenger Syndrome A Multicenter, Double-Blind, Randomized, Placebo-Controlled Study. Vasc. Med. 4, 48-54. doi; 10.1161/CIRCULATIONAHA.106.630715

Nazzareno, G., Alessandra, M., Luca, N., Massimiliano, P., Maria, L. B., and Angelo, B. (2009). A meta-analysis of randomized controlled trials in pulmonary arterial hypertension. Eur. Heart J. 30, 393-403. doi: 10.1093/eurheartj/ehp022

Nazzareno, G., Marc, H., Jean-Luc, V., Simon, G., Irene, L., Adam, T., et al. (2016). 2015 ESC/ERS guidelines for the diagnosis and treatment of pulmonary hypertension. Eur. Heart J. 37, 69-119. doi: 10.1093/eurheartj/ehv317

Nazzareno, G., Horst, O., Ronald, J. O., Fernando, T., Adaani, F., Hossein, A. G., et al. (2018). Ambrisentan for the Treatment of Pulmonary Arterial Hypertension Results of the Ambrisentan in Pulmonary Arterial Hypertension, Randomized, Double-Blind, Placebo-Controlled, Multicenter, Efficacy (ARIES) Study 1 and 2. Vasc. Med. 7, 3010-3019. doi: 10.1161/ CIRCULATIONAHA.107.742510

Nickel, N., Golpon, H., Greer, M., Knudsen, L., Olsson, K., Westerkamp, V., et al. (2012). The prognostic impact of follow-up assessments in patients with idiopathic pulmonary arterial hypertension. Eur. Respir. J. 39, 589-596. doi: 10.1183/09031936.00092311

Raymond, L. B., Dave, P. M., Mardi, G., Robert, P. F., Aimee, J. F., Christopher, S. C., et al. (2010). Predicting survival in pulmonary arterial hypertension: insights from the Registry to Evaluate Early and Long-term Pulmonary Arterial Hypertension Disease Management(REVEAL). Circulation 122, 164-172. doi: 10.1161/CIRCULATIONAHA.109.898122

Robyn, J. B., Dunbar, I., Guillermo, G., Andras, S., Andrzej, R., Alberto, E. G., et al. (2011). A Randomized, Double-Blind, Placebo-Controlled, Dose-Ranging Study of Oral Sildenafil Citrate in Treatment-Naive Children With Pulmonary Arterial Hypertension. Pediatr. Cardiol. 7, 324-334. doi: 10.1161/ CIRCULATIONAHA.110.016667

Robyn, J. B., Maurice, B., Tomas, P., Gary, L., Irina, K., Min, Z., et al. (2014). STARTS-2: Long-Term Survival With Oral Sildenafil Monotherapy in Treatment-Naïve Pediatric Pulmonary Arterial Hypertension. Circulation 129 (19), 1914-1923. doi: 10.1161/CIRCULATIONAHA.113.005698

Ronald, J. O., Nazzareno, G., Horst, O., Fernando, T., Adaani, F., Hossein, A. G., et al. (2009). Long-Term Ambrisentan Therapy for the Treatment of Pulmonary Arterial Hypertension. J. Am. Coll. Cardiol. 54 (21), 1971-1981. doi: 10.1016/j.jacc.2009.07.033

Shannon, E. B., Susan, M., Laura, C. M., Sharon, R., John, W., Ronald, P., et al. (2010). Long-term Outcomes with Ambrisentan Monotherapy in Pulmonary Arterial Hypertension. J. Cardiac Fail. 16 (2), 121-136. doi: 10.1016/ j.cardfail.2009.09.008 
Shunji, Y., Kunio, S., Ryutaro, S., Takayuki, I., Narumi, A., and Hiromu, N. (2012). Long-term safety and efficacy of ambrisentan in Japanese adults with pulmonary arterial hypertension. Curr. Med. Res. Opin. 28 (6), 1069-1076. doi: 10.1185/03007995.2012.685930

Sitbon, O., McLaughlin, V. V., Badesch, D. B., Barst, R. J., Black, C., Galiè, N., et al. (2005). Survival in patients with class III idiopathic pulmonary arterial hypertension treated with first line oral bosentan compared with an historical cohort of patients started on intravenous epoprostenol. Thorax 60, 1025-1030. doi: 10.1136/thx.2005.040618

Stephen, M. B., Sanjiv, K., Dean, W., Kandasamy, R., Stephen, W., Victor, R., et al. (2007). Pediatric pulmonary hypertension: Roles of endothelin-1 and nitric oxide. Clin. Hemorheol. Microcirc. 37 (1-2), 111-120.

Wangzong, H., and Jiahong, L. (2014). Advanced medical statistics (Beijing: Beijing Science Press).

Wouter, J., Anco, B., Monika, B., Daniel, M. R., Berthold, S., Pieter, E. P., et al. (2010). Long-term outcomes in pulmonary arterial hypertension in the firstline epoprostenol or first-line bosentan era. J. Heart Lung Transplant. 29 (10), 1150-1158. doi: 10.1016/j.healun.2010.05.011
Xiantao, Z., and Xuequn, R. (2017). STATA was used for Meta analysis (China: China union medical college press).

Zhi-Cheng, J., Xi-Qi, X., Zhi-Yan, H., Yan, W., Ke-Wu, D., Hao, W., et al. (2007). Registry and survival study in Chinese patients with idiopathic and familial pulmonary arterial hypertension. Chest 132 (2), 373-379. doi: 10.1378/ chest.06-2913

Conflict of Interest: The authors declare that the research was conducted in the absence of any commercial or financial relationships that could be construed as a potential conflict of interest.

Copyright (C) $2020 \mathrm{Li}$ and Li. This is an open-access article distributed under the terms of the Creative Commons Attribution License (CC BY). The use, distribution or reproduction in other forums is permitted, provided the original author(s) and the copyright owner(s) are credited and that the original publication in this journal is cited, in accordance with accepted academic practice. No use, distribution or reproduction is permitted which does not comply with these terms. 